\title{
Author Correction: The true cost of labour must be worker-defined
}

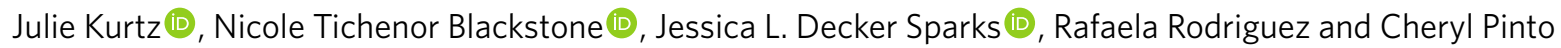

Correction to: Nature Food https://doi.org/10.1038/s43016-021-00369-8, published online 20 September 2021.

In the version of this Correspondence originally published, there were errors in the labels of Fig. 1. Specifically, the text in the middle of the diagram, reading "Pass on premium as bonus" originally read "... as bonds." The vertical text on the upper right, reading "Pay buyer premium" originally read "...user premium." The errors have been corrected in the online version of the paper.

Published online: 30 September 2021

https://doi.org/10.1038/s43016-021-00397-4

(c) Springer Nature Limited 2021 